\title{
The effect of emigration on home-country political institutions
}

\section{Migrants can have positive political effects on their home countries' institutions}

Keywords: migration, institutions, democracy, development

\section{ELEVATOR PITCH}

The number of immigrants from developing countries living in richer, more developed countries has increased substantially during the last decades. At the same time, the quality of institutions in developing countries has also improved. The data thus suggest a close positive correlation between average emigration rates and institutional quality. Recent empirical literature investigates whether international migration can be an important factor for institutional development. Overall, the findings indicate that emigration to institutionally developed countries induces a positive effect on home-country institutions.

\section{KEY FINDINGS}

\section{Pros}

๑ International migration to democratic countries can improve political institutions at home.

๑ Positive effects can occur through several channels, e.g. transfer of new ideas and political norms, return or circular emigration, and remittances.

๑ In general, macro studies find positive global effects if migrants' destination countries are democratic.

( Micro studies generally focus on a single country, and find positive effects of some specific channels, such as transfer of norms and return migration.

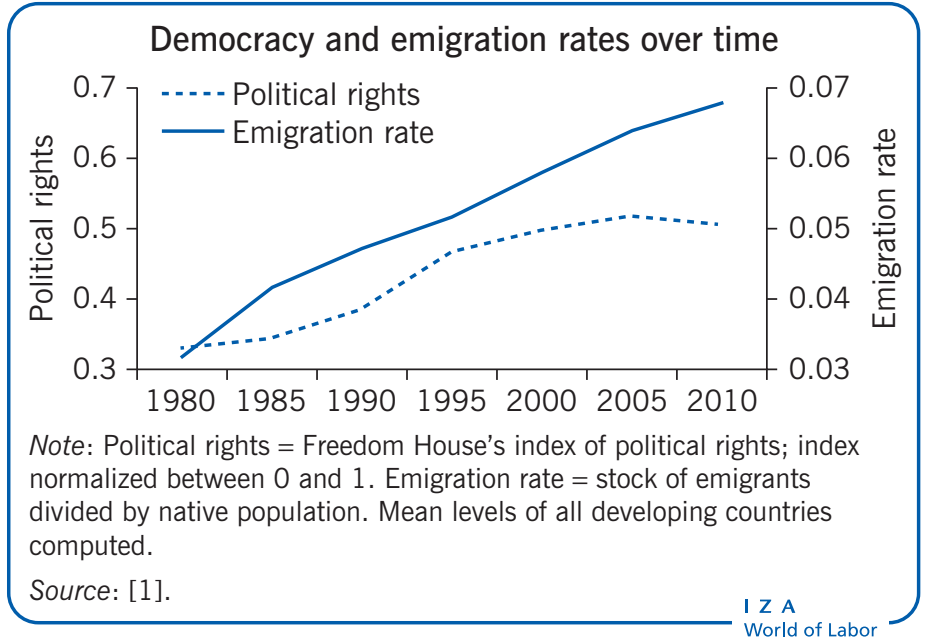

\section{Cons}

- International migrants can induce negative effects in the home country if they emigrate to less democratic countries.

- Self-selection of migrants, in terms of education or ethnicity, can induce negative effects on institutions, as such individuals tend to be more politically engaged in their home country.

- The main channels and specific mechanisms through which emigration affects institutions are not always empirically well-identified.

\section{AUTHOR'S MAIN MESSAGE}

Emigration can affect home-country institutions in several ways, and its effects can be positive or negative depending on the characteristics of the emigrants, the destination country, and whether emigrants maintain strong ties and a sense of belonging to their home country that induces them to influence the political process from abroad. Cross-country studies generally find a positive effect of emigration on institutional quality in the home country. However, the induced democratization process from abroad can only occur if the host country implements policies that allow immigrants to integrate and participate in social and economic activities so that they can acquire the new values and norms that can be transmitted to the home country. 


\section{MOTIVATION}

Political institutions are very important for economic growth and development in general. It is therefore vital to understand what determines the quality of such institutions. Only a relatively small number of research papers argue that international migration is an important determinant of the quality of institutions in the home country, and these try to test the effects of international migration empirically.

International migration can improve institutions through several direct and indirect channels: (i) the transfer of political norms; (ii) voting from abroad; (iii) financial remittances; (iv) return migration; and (v) lobbying activities from abroad (e.g. whereby migrants might lobby the host-country government to encourage, or block, financial aid to their home country). At the macro level, recent key studies consider the overall impact of emigration on institutional quality and discuss the possible effects through which emigration may affect institutions in the home country, but without disentangling those effects. In contrast, the micro literature focuses on one specific country and investigates more thoroughly the channels through which emigration may affect institutions.

\section{DISCUSSION OF PROS AND CONS}

\section{Trends in international migration and political institutions}

According to the UN Global Migration Database, the number of international migrants increased from 75 million in 1960, to 214 million in 2010. Given the population growth rate, this represents a slight increase in relative terms: from $2.5 \%$ to $3.0 \%$ of the world population. The picture changes when looking at international migration to developed countries. The share of foreign-born individuals in the total population of high-income countries has tripled since 1960 (and doubled since 1985) [2]. Most of these migrants have emigrated from non-OECD countries. A recent database that considers international migration to 20 OECD destination countries, from 1980 to 2010, reveals that the average emigration rate from developing countries to these 20 OECD countries increased by $113 \%$ over this period.

At the same time, standard political institution indicators, such as Freedom House's indices of political rights and civil liberties, increased by $53 \%$ and $60 \%$ respectively, over the same period (see the illustration on p.1). The data therefore indicate a close positive correlation between openness to migration, as measured by the average emigration rate, and institutional quality. This leads to the question of whether there is any sort of causal relationship between emigration and institutions. Also, importantly, whether migrants affect the quality of institutions in their home country and, if so, how?

\section{The relationship between democracy and emigration}

Emigration can affect political institutions in the home country through several channels, and can affect the supply side of the quality of institutions, the demand for (better) quality institutions, as well as the interaction between the two.

On the supply side, the quality of institutions depends, to a large extent, on the availability of appropriately qualified individuals. However, should such individuals choose to leave their country at some point, a potential result could be the persistence of corrupt regimes 


\section{Indicators of democracy}

Freedom House's political rights and civil liberties indicators: these are based on measures proposed by analysts who score countries using information collected through various sources such as news reports, non-governmental organization and think tank evaluations, and surveys administered to a large number of professionals. For the political rights index, the questions used in the scoring process are grouped into three sub-categories: electoral processes, political pluralism and participation, and functioning of the government. For the civil liberties index, questions are grouped into four subcategories: freedom of expression and belief; association and organization rights; rule of law and personal autonomy; and individual rights. The sum of each country's subcategory scores translates to a rating from 1 to 7 , with a higher score indicating more freedom.

Economic Freedom of the World: this is a measure that indicates the degree of economic freedom in a country. It is based on components belonging to five main areas: (i) size of government; (ii) legal system and security of property right; (iii) access to sound money; (iv) freedom to trade internationally; (v) regulation of business, labor, and capital markets. The ratings are determined by combining real indicators with answers to survey questions taken from other primary sources (such as the Global Competitiveness Report, and the World Bank's Doing Business project). The overall index ranges from 0 to 10, with a higher score indicating more freedom.

Polity 2 indicator of the Polity IV Project of democracy: this is a combined score that reflects several aspects such as: the presence of institutions and procedures through which citizens can express effective preferences about alternative policies and leaders; the existence of institutionalized constraints on the exercise of power by the executive power; and the guarantee of civil liberties to all citizens in their daily lives and in acts of political participation. It ranges from -10 to +10 .

Source: Docquier, F., E. Lodigiani, H. Rapoport, and M. Schiff. "Emigration and democracy." Journal of Development Economics 120 (2016): 209-223.

or political instability. Indeed, individuals who decide to emigrate can be "self-selected" along a variety of dimensions.

First, emigrants can typically be positively self-selected on the basis of education. As it is plausible to suppose that individuals who are more educated tend to be more politically involved and contribute more to public policy debates, emigration is likely to negatively affect the quality of political institutions. At the same time, migration prospects might raise the incentives of individuals to invest in personal education as a means of maximizing the probability of emigrating, under the assumption that they will benefit from higher wages and a better quality of life [3], as well as use their talents more productively [4]. Such effects on the skill distribution could mitigate the negative effects of skilled emigration on political institutions, but only if a sufficiently high proportion of individuals who made such investments finally stay in their home country.

Second, migrants are typically self-selected on the basis of their ethnicity, with there being a predominant representation of ethnic minorities among emigrants. Again, as it is plausible to suppose that ethnic minorities are quite politically engaged and therefore more likely to oppose their governments, the emigration of minorities could induce a less pluralistic society, with resulting negative effects on democratic institutions. This is 
referred to in the literature as the "exit voice" model, where emigration decisions can be seen as an exit option that allows people to leave autocratic or discriminatory regimes [5].

On the demand side, however, the decision to emigrate could modify and decrease the incentive to "voice" (in terms of voting or agitating for change), which could result in less political pressure for reforms. The result of this would be similar if those who choose to remain receive financial remittances from family members who have previously emigrated. These remittances could act as a safety net and decrease the incentive to demand reforms. In this case, emigration negatively affects political institutions in the home country. Alternatively, emigrants can maintain strong ties and a sense of belonging to their home country that induces them to "voice" from abroad, and so influence the political process in their home country.

Migrants can also engage in lobbying activities (e.g. to encourage or block financial aid, or impose an economic embargo). They can vote from abroad, or return home to vote when absentee voting is not permitted. They can even lobby to obtain the right to vote, or to run as candidates in their country of origin. They can also send remittances to finance their preferred political parties and politicians. Their political contributions can be made directly or through their family at home. In addition, remittance recipients can be influenced by the remitter's political preferences in their decision to vote.

Overall, emigration can demand greater accountability and induce political change and more democratic government.

A related channel refers to a "transfer-of-norms" mechanism, through which migration increases the home-country population's exposure to democratic values and norms, and stimulates greater demand for better institutions at home. Several studies in the sociological literature show that, during their stay abroad, emigrants are exposed to different values, norms, narratives, and other forms of behavior that are specific to the host country [6]. They form networks and are exposed to media in the host country. They can also acquire education in the host country, thus becoming aware of new economic and institutional conditions and models, etc.

After a certain period of residence in a new country, migrants accommodate new practices that can have substantial impacts on their country of origin. In particular, they can absorb new political values in a broader sense, whether these are attitudes toward democracy, corruption, or gender parity and female political participation. Within such a context, migrants can directly transfer social and institutional norms and practices by simply being in contact with their family members and friends back home. They can take part in diaspora networks, or they can return to their home country, bringing with them these new values, and so becoming both a source of supply and demand for changing institutions.

Of course, the transfer of new political attitudes depends on the political environment in the host country, and whether those countries are more democratic and liberal, and less corrupt, or more open to gender parity than the home country.

\section{Empirical evidence}

An emerging strand of literature attempts to empirically analyze the effect of emigration on political institutions, at both macro and micro levels. Studies at the macro level consider 
the overall effect of emigration on political institutions, including both the supply- as well as demand-driven effects. Studies at the micro level generally test for different channels at work and consider mainly demand-driven effects.

In general, identifying the causal effect of emigration on institutional quality is not an easy task, for several reasons. First, there can be some omitted variables, or unobserved characteristics (such as religious and ethnic variables), which can simultaneously affect both emigration and institutions. Second, a "reverse causality" problem can influence the estimations: for example, more democratic countries can "let their people go" more easily; in addition, a "lack of democracy" can also act as a strong push factor for emigration. Third, as has been noted earlier, migrants can be self-selected along several dimensions, including their destination choice: that is, people will try to emigrate to countries that have political values that resonate with their own. For example, they may move to more democratic countries if they have a strong preference for democracy.

A standard way of solving these kinds of problems, and to establish causal effects, is to identify instrumental variables, that is, variables that are strongly correlated with the emigration decision, but not directly correlated with the quality of institutions (or not indirectly correlated through omitted variables). Possible instrumental variables in this respect are unexpected shocks, such as natural disasters or historical events, which can cause exogenous variation in migration movements. At the first stage of analysis, instrumental variables are applied to predict migration; at the second stage, predicted migration can be used to explain institutional quality. In order to establish a causal relationship, most of the studies presented in the following sections rely on this type of analysis.

In certain cases, the availability of panel data (i.e. multiple cases observed at two or more time periods) makes it possible to use additional empirical methods that allow to control for unobserved characteristics and the persistence of the quality of the institutions, and to use past values and time differences of the variable of interest as instrumental variables.

\section{A cross-country approach}

A pioneering study related to the literature on migration and institutions adopts a crosscountry approach and considers panel data. It demonstrates that foreign-trained students promote democracy in their home country if their education is acquired in host countries that are democratic [7]. Even if this study does not empirically disentangle the mechanisms through which host-country education may affect democracy in the home country, it discusses several possible channels (which are close to those previously discussed for emigration). In addition, the study underlines the importance of foreign-educated leaders, who may enter into structural reforms in the home-country with higher probability, and keep up with the more democratic countries where they studied.

A natural extension of considering how foreign-educated leaders can be extremely important in influencing the reform of a country, would be to consider the possibility of how all emigrants could also be important agents in influencing institutional quality, even from abroad. Few studies have relied on cross-country data in order to perform a larger-scale exercise in order to estimate the global effect of emigration on political institutions, including all possible channels. These studies generally find a positive effect of emigration on institutional quality. One of the pioneering studies in this respect is a cross-sectional study that estimates a specification where the dependent variable is 
the institutional outcome, measured through the six World Bank governance indicators. These are: voice and accountability; political stability and absence of violence/terrorism; government effectiveness; regulatory quality; rule of law; and control of corruption [8]. After taking into account standard determinants of institutional outcomes (e.g. percentage of Muslims and Catholics in the population, legal origin, ethno-linguistic fractionalization, GDP per capita, etc.), measures of the resident human-capital stock and the emigrant human-capital stock are also included. The study shows a general positive effect of the direct impact of human capital, a positive effect of emigration on political institutions (i.e. voice and accountability, political stability, and absence of violence), and a negative effect of emigration on economic institutions (i.e. government effectiveness, regulatory quality, and control of corruption). In addition, the overall effect of moving an educated individual from the resident human capital stock to the emigrant human capital stock positively affects political institutions, but decreases the quality of economic institutions, which are more related to a country's economic productivity and policy implementation. However, although this study represents a first attempt at estimating the effect of emigration on institutional quality, these results are based mainly on correlational evidence.

A further step has been achieved by a more recent study [1]. This study considers a panel framework and investigates whether the positive relationship between openness to emigration and institutional quality holds once it has taken into account a number of important covariates (such as past values of institutional quality, human capital, income per capita, legal origin, geographic regions, ethnic fractionalization, trade openness, foreign aid, and geographic characteristics) that have been shown to determine institutions. The total emigration rate to 20 OECD (major destination) countries is considered as the main variable of interest. Institutional quality is measured by Freedom House's political rights and civil liberties indicators, the Simon Fraser Institute's Economic Freedom of the World indicator (which are de facto institutional indicators), and the "Polity 2" indicator of the Polity IV Project, which is an indicator of de jure institutional quality. It is found that openness to emigration has a positive impact on democracy at home, when de facto (three out of four) institutional indicators are considered.

Three complementary instrumental variable approaches are used in this study to establish a causal relationship between emigration and institutions. These are: (i) a model predicting a country's total emigration rate, which uses a set of variables that are important determinants of bilateral migration stocks (such as variables that indicate whether the two countries share a language, whether a guest-worker program was in place between 1945 and the 1980s, and the bilateral distances between the biggest cities of the two countries, with the assumption that larger distances imply higher migration costs); (ii) instrumental variables, such as weather-based variables (associated with an indicator of country size), on the assumption that natural disasters and weather anomalies can cause migration; and (iii) past values and time differences of the particular variable that is of interest.

While the previous work discussed above cannot distinguish between supply versus demand forces (as explained earlier), a more recent study focuses on the supply-side effects and considers the impact of the migration experience of leaders on the quality of government [9]. New pieces of information have been collected on the migration history of leaders before they became the head of a developing country between 1960 and 2004. Four different reasons for migration are considered: (i) migration for educational study; (ii) migration in the frame of diplomatic missions; (iii) military reasons; (iv) exile abroad. After having controlled for several leader characteristics (e.g. gender, education, 
professional activity) the results show that the leaders' migration experience does not necessarily affect the quality of political institutions, whereas leaders who have studied abroad have a positive impact on political institutions in countries that start from a low level of democracy.

\section{Channels of influence: A micro approach}

While macro studies capture the general effects of emigration on institutions, some recent empirical work focuses on a particular country. Using micro-level data, these studies are able to investigate some specific channels through which emigration can affect political institutions in the home country. In particular, this includes the transfer of political norms, return migration, and remittances.

One pioneering study has been conducted in Cape Verde, which is an African island with a very high rate of skilled emigration (approximately 70\%) [10]. Cape Verde, which was a Portuguese colony until 1975, benefited from good governance compared to sub-Saharan Africa standards, and its emigration flows are directed toward two main destinations: Portugal and the US. The study focuses on a "postcard voting experiment," in which Cape Verdean residents were asked to answer a survey on perceived corruption in public services. This provided a possibility to make the results publicly available in the national media if at least $50 \%$ of the respondents mailed back a prepaid postcard to the organizers of the survey. Written on the postcard was "I wish that the conclusions of the survey on the quality of national public services (health, education, justice...), conducted by the University of Oxford (UK) in the first months of 2006, to 1,000 households in the islands of Santiago, São Vicente, Santo Antão, and Fogo, are made public in the Cape Verdean media." The message was associated with a statement made by interviewers to each respondent: "It is very important that you put the postcard in the mail if you want that Cape-Verdeans are able to require higher quality in the public services of CV" [10].

An analysis of the determinants of the probability for a respondent to mail the postcard back (which is effectively a behavioral measure of the demand for greater political accountability), found that the proportion of international migrants (including both current and return migrants) from within the spatial area of the respondent's place of residence, has a positive effect on the probability of mailing the voting postcard. The result holds especially for international return migrants from the US-whereas the effect of migrants returning from Portugal is negative. This suggests two things. First, that the effect of emigration on the demand for greater political accountability depends on the quality of governance of the migrants' country of destination. Second, that the impact of return migrants is stronger than that of current emigrants, which only indirectly influences friends or relatives in the home country. Returnees, instead, can have a direct effect on the outcome due to their voting behavior, but also an indirect one due to their influence on their family and friends, which is in line with the transfer-of-norms channel. The two kinds of effects (direct or indirect), are not however empirically disentangled.

Another study, focusing on Mexico, finds evidence that international migration to the US contributes to the democratization process in Mexico [11]. In particular, international migration significantly increased the probability of a party in opposition to the former state party-the Institutional Revolutionary Party (PRI) winning a municipal election for the first time in the period 2000-2002. At that time, more than two-thirds of Mexican municipalities were still governed by the old state PRI, which had been the main ruling 
party since 1929 (until 2000 when Vicente Fox won the presidential election, defeating the PRI). In this framework, it was shown that a higher proportion of migrant households increased the probability of an opposition party winning the local election for the first time in municipalities governed historically by the PRI. Conversely, in municipalities where the opposition party was already in power, migration had no effect on electoral outcomes. This suggests that international migration is influential in inducing a process of democratization. Once this is in place, migration has no further effect on electoral results.

Two main channels of transmission through which migration could affect democratization in Mexico are discussed in this study. First, the transfer of new ideas and norms from the host country (i.e. the US) to the home country, through migrants' social networks and return migration. Second, remittances that contribute toward weakening the "clientelistic" relationship between the long-term party in power and the voters-that is, for as long as voters' disposable income rises due to remittances, the "clientelistic" transfers in exchange for a vote should also increase. If political parties face budget constraints, this system would become financially unsustainable. As the analysis shows that returnees do not play a significant role in political outcomes, this can be interpreted as a weak role of the transfer-of-norm channel compared to financial remittances. Unfortunately, the two different effects are not empirically disentangled, thus making it difficult to identify the precise mechanism at work.

Yet, another study on Mali considers the effect of the stock of return migrants (from African and non-African countries) on political outcomes [12]. In particular, data on municipal elections in 1998 and 2009 are used to test whether political outcomes, measured either as participation rate or as an indicator of electoral competitiveness (such as a measure of the fragmentation of the votes among the competing lists in the race and a measure of the difference between the share of votes obtained by the winning list and the share of votes obtained by the second list) are influenced by return migration. The results show that Malian returnees positively affected the rate of electoral participation, thus contributing to enhanced democracy. Importantly, this result holds when emigrants return from nonAfrican countries while no robust impact of returnees from African countries is found. The same analysis is conducted on the impact of returnees on different measures of electoral competitiveness. Again, the share of returnees from non-African countries in the population, aged over 18 , is correlated positively with stronger electoral competitiveness, but the results are less robust than the results on participation. Interestingly, it is found that the impact of returnees on political outcomes is not only driven by returnees' specific electoral behavior (e.g. they participate more), but, in the spirit of the transfer-of-norms channel, they diffuse new electoral behavior to non-migrants in Mali.

Generally, not only returnees but also migrants from abroad can transfer new values and ideas, as has been found in a recent study on Moldova, a former Soviet state [13]. Moldova became independent in 1991 and suffered from a volatile democratic transition, which saw the Communist Party return to power in 2001. Only quite recently, in the parliamentary elections of 2009 and 2010, has a shift of political power occurred from the Communist Party to the Alliance for European Integration, which is a liberal four-party coalition. This study found that emigration to Western countries decreased support for the Communist Party in the parliamentary elections in Moldova, thus contributing to establishing new liberal voters and parties that are more democratic. The study exploited a "quasi-natural" experiment situation that allowed testing for the impact of emigration on the change of political attitudes and voting behavior of the resident population at the community 
level. There was almost no emigration in Moldova prior to the Russian financial crisis of 1998. Within a few years after the crisis, a period of mass emigration occurred, thus providing the possibility of controlling for pre-migration voting behavior. In addition, emigration occurred to two main destinations with very different democratic traditions and political ideologies, thus permitting the authors to control for destination-specific effects. About $40 \%$ of emigrants left for democratic countries in Western Europe, while $60 \%$ emigrated to less-democratic countries in the East, particularly Russia. The quasinatural experiment and bi-polar migrational setting allowed for a causal interpretation of the results, which indicate a significant and negative effect of emigration to Western countries on the share of votes for the Communist Party in the 2009-2010 elections. An opposite effect (but weaker and less robust) is found for emigration to the East. In addition, the analysis provides evidence that the effect of emigration works through the transfer-of-norm channels of current migrants, rather than through return migration or monetary remittances.

Along the same lines, a study on Mozambique examined whether return or current migrants could transfer more democratic values and ideas, which may then have affected political attitudes and political participation of residents through social networks. Using household-level survey data collected around the presidential election in 2009, different measures of political attitudes (e.g. interest in political issues, preference for democracy, behavioral measures that reflected demand for political accountability) and different types of networks were considered. The networks were differentiated between: (i) geographical networks (how many households had at least one member with migration experience); (ii) family networks (the proportion of family migrant members in the network); and (iii) "chatting" networks (the proportion of migrant households with whom the respondent had regular contact). The results show that individual political attitudes were strongly influenced by chatting networks and, to a lesser extent, by family and geographical networks. The effects seem to depend on networks that include current migrants.

\section{LIMITATIONS AND GAPS}

Different data (micro and macro) and methodologies have been considered to identify the effect of emigration on home-country political institutions. While the macro approach tends to test the overall impact of emigration, which includes all possible channels of influence, the micro literature focuses on one particular country and tries to identify separately the channels through which migration may affect political outcomes in the country of origin.

Results appear to be quite mixed and context-specific. While most of the studies underline the importance of the transfer-of-norms channel, there is no clear evidence for whether current migrants or returnees are the main drivers. The same applies to financial remittances. Even if they can play an important role in shaping political behavior, no empirical evidence considers their effects separately. Further research should be undertaken to better disentangle all the possible channels, in order to understand the most relevant ones.

Micro studies are a step in the right direction. However, new research is needed that tries to examine specific mechanisms and to generalize the existing results. In this sense, macro studies allow for cross-country comparisons and are very important in providing an overall picture. However, given that institutions are very persistent and, unfortunately, take a long time to evolve, they rely mostly on cross-country variation, since they are 
based on a quite short time span (around 30 or 40 years). This is one of the reasons why micro studies are particularly relevant, even if, as stated, they are usually limited by the use of a single country and provide context-specific results.

\section{SUMMARY AND POLICY ADVICE}

The existing literature shows the importance of international migration acting as a political agent working to shape institutions in the country of origin. Whereas macro studies show the positive global effect of emigration, micro studies try to disentangle the channels through which migrants can become important in shaping political outcomes in the place of origin. Even if more research is needed to clarify the mechanisms and effects of international migrants on political outcomes at home, it is recognized that they could be important agents of democratization.

Thus, policymakers should take into account that migration policies, both at the origin and the destination, may promote the role of migrants as transnational political agents. For example, favoring dual citizenship will allow migrants, on the one hand, to integrate and naturalize in their destination country, and on the other hand, to maintain a sense of belonging to their original country, to maintain contacts with friends and relatives more easily, and to send remittances. Home countries can favor migrants' political participation by allowing external voting. At the same time, host countries can help to support the organization of external voting. International organizations could also play an important role in implementing voting programs from abroad, especially following post-conflict elections.

Finally, the induced democratization process from abroad can only occur if migrants have the possibility of integrating and participating in the social and economic activities in the host country. Only in that way they can they acquire new norms and political values, which can be transmitted to the country. Therefore, integration policies, such as language or employment training in the host country, are crucial in helping the successful integration of migrants (while considering, of course, that the integration needs of each migrant depends on her/his level of education and experience).

Overall, policymakers and the international community should consider the importance of international migrants as key political agents when setting their political agendas.

\section{Acknowledgments}

The author thanks two anonymous referees and the IZA World of Labor editors for many helpful suggestions on earlier drafts. Previous work of the author contains a larger number of background references for the material presented here and has been used intensively in all major parts of this article [1].

\section{Competing interests}

The IZA World of Labor project is committed to the IZA Guiding Principles of Research Integrity. The author declares to have observed these principles.

(C) Elisabetta Lodigiani 


\section{REFERENCES}

\section{Further reading}

Chauvet, L., F. Gubert, and S. Mesplé-Somps. Do Migrants Adopt New Political Attitudes from Abroad? Evidence Using a Multi-sited Exit-poll Survey during the 2013 Malian Elections. DIAL Working Paper, 2015.

Kapur, D. Diaspora, Development and Democracy: The Domestic Impact of International Migration from India. Princeton, NJ: Princeton University Press, 2010.

\section{Key references}

[1] Docquier, F., E. Lodigiani, H. Rapoport, and M. Schiff. "Emigration and democracy." Journal of Development Economics 120 (2016): 209-223.

[2] Docquier, F., and H. Rapoport. "Globalization, brain drain, and development." Journal of Economic Literature 50:3 (2012): 681-730.

[3] Beine, M., F. Docquier, and H. Rapoport. "Brain drain and human capital formation in developing countries: Winners and losers." The Economic Journal 118:528 (2008): 631-652.

[4] Mariani, F. "Migration as an antidote to rent-seeking?" Journal of Development Economics 84:2 (2007): 609-630.

[5] Hirschman, A. Exit, Voice, and Loyalty; Responses to Decline in Firms, Organizations, and States. Cambridge, MA: Harvard University Press, 1970.

[6] Levitt, P. The Transnational Villagers. Berkeley, CA: University of California Press, 2001.

[7] Spilimbergo, A. "Democracy and foreign education." American Economic Review 99:1 (2009): 528-543.

[8] Li, X., J. McHale, and X. Zhou. Does Brain Drain Lead to Institutional Gain? A Cross-country Empirical Investigation. Queen's University Working Paper, 2013.

[9] Mercier, M. "The return of the prodigy son: Do return migrants make better leaders?" Journal of Development Economics 122 (2016): 76-91.

[10] Batista, C., and P. C. Vicente. "Do migrants improve governance at home? Evidence from a voting experiment." World Bank Economic Review 25:1 (2011): 77-104.

[11] Pfutze, T. "Does migration promote democratization? Evidence from the Mexican transition." Journal of Comparative Economics 40:2 (2012): 159-175.

[12] Chauvet, L., and M. Mercier. "Do return migrants transfer political norms to their origin country? Evidence from Mali.” Journal of Comparative Economics 42:3 (2014): 630-651.

[13] Omar Mahmoud, T., H. Rapoport, A. Steinmayr, and C. Trebesch. The Effect of Labor Migration on the Diffusion of Democracy: Evidence from a Former Soviet Republic. IZA Discussion Paper No. 7980, 2014.

\section{Online extras}

The full reference list for this article is available from:

http://wol.iza.org/articles/effect-of-emigration-on-home-country-political-institutions

View the evidence map for this article:

http://wol.iza.org/articles/effect-of-emigration-on-home-country-political-institutions/map 